\title{
Gemelos onfalópagos con síndrome de transfusión Gemelo-gemelar. Preparación y técnica para una separación exitosa en Chile*
}

\author{
Drs. ALICIA EBENSPERGER O. ${ }^{1}$, AQUILES HACHIM G. ${ }^{1}$, RICARDO YÁÑEZ M. ${ }^{2}$, \\ CRISTIÁN GAMBOA C. ${ }^{2}$, ALEJANDRO ZAVALA B. ${ }^{1}$, CLAUDIO ARRETZ V. ${ }^{3}$, \\ CARLOS GIUGLIANO V. ${ }^{4}$, PAOLA OSTERMANN W. ${ }^{7}$, CAROLINA BAERESWYL T. ${ }^{7}$, \\ MIGUEL VEGA P. ${ }^{7}$, AIDEÉ OSSES C. ${ }^{7}$, ROSEMARY HEIDER M. ${ }^{7}$, CLAUDIO DAZA B. ${ }^{5}$, \\ ROSENDO LOBOS A. ${ }^{5}$, RODRIGO PARRA R. ${ }^{6}$, JORGE MARTÍNEZ C. ${ }^{2}$
}

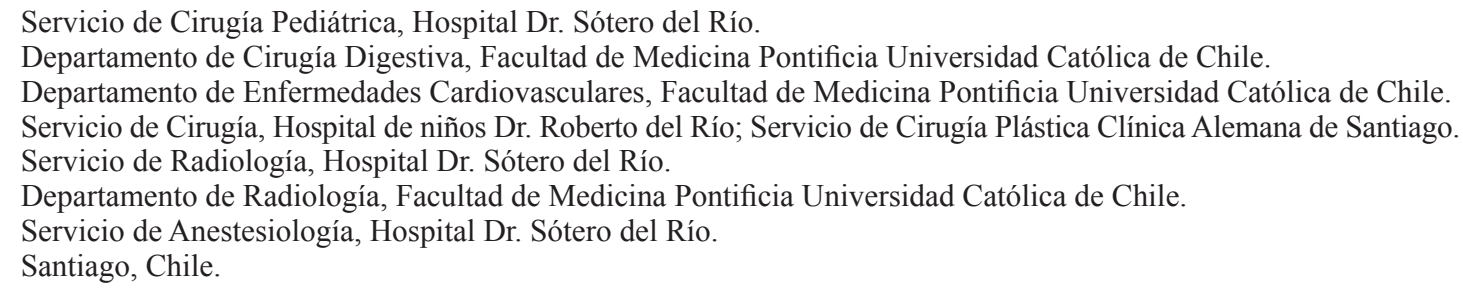

\section{Omphalopagus conjoined twins with a twin-twin transfusion syndrome. Result of a multidisciplinary and successful separation in Chile}

\section{Introducción}

Los gemelos fusionados se han descrito desde épocas pre-cristianas ${ }^{1}$ y la primera separación exitosa data de $1689^{2}$. El apelativo de "siameses" se originó en la historia de dos hermanos fusionados nacidos en Siam en 1811, quienes se casaron con dos hermanas, vivieron 63 años y tuvieron descendencia $^{1}$. Su incidencia es de 1/50.000 embarazos y aproximadamente de 1 caso cada 250.000 nacidos vivos. Son gemelos monocigóticos, correspondiendo el $70 \%$ de los casos a pacientes de sexo femenino. No hay descrito un factor hereditario o pre-disponente identificado ${ }^{3-5}$. La mayoría fallece in-útero o precozmente después del parto con una sobrevida al año no mayor al $10 \%-20 \%^{2-4}$. Muy pocos tienen la posibilidad técnica de separación ${ }^{2-5}$. Se los clasifica en ocho tipos según el sitio de unión (Figura 1 y Tabla 1).

$\mathrm{Su}$ infrecuencia y la variabilidad entre ellos, determinan que su separación constituya uno de los mayores desafíos médico-quirúrgicos, ya que existen pocos casos comparables entre sí y además escasos profesionales con experiencia acumulada en el tema. Se trata de la primera separación quirúrgica de gemelos siameses onfalópagos con un Síndrome de Transfusión Gemelo-Gemelar (STGG) realizada en nuestro país.

Presentamos la preparación, estudio y aspectos de la técnica quirúrgica de una separación quirúrgica electiva de dos hermanos gemelos siameses onfalópagos con un síndrome de transfusión gemelo-

\footnotetext{
*Recibido el 27 de Agosto de 2009 y aceptado para publicación el 21 de Octubre de 2009.

Correspondencia: Dra. Alicia Ebensperger O., Dr. Jorge Martínez C. Marcoleta 352, Santiago, Chile.

Fax: 56-2-3543462

E-mail: aebensperger@ssmso.cl; jmartin@med.puc.cl
} 


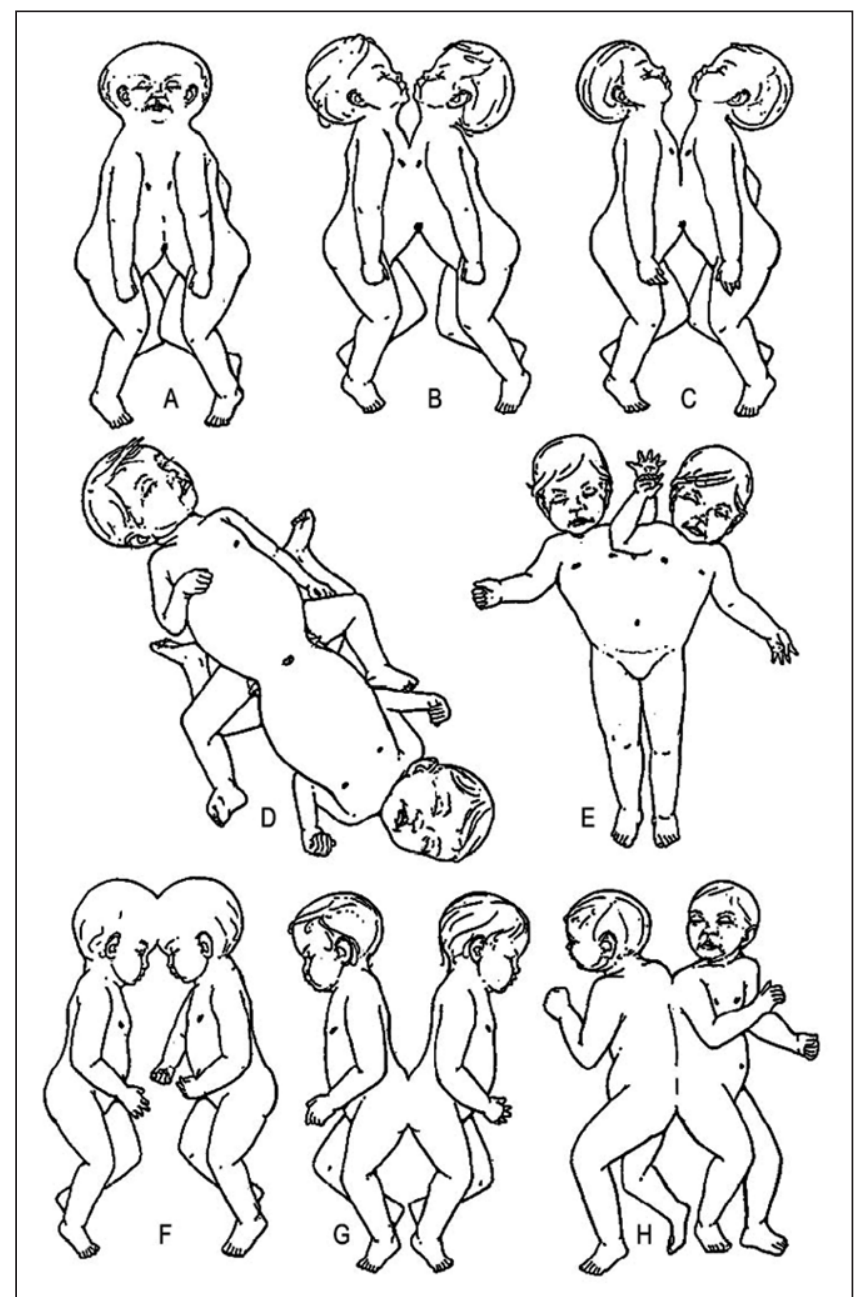

Figura 1. Clasificación de gemelos siameses según sitio de unión. A: Cefalópagos; B: Toracópagos; C: Onfalópagos; D: Isquiópagos; E: Parápagos; F: Craniópagos; G: Pigópagos; H: Raquípagos (Reproducido con autorización de Elsevier Limited; The Boulevard, Langford Lane, Kidlington, Oxford, OX5 1 GB, UK.). gemelar (STGG), a través de la fusión de sus hígados. El diagnóstico y evaluación de factibilidad técnica se realizó por estudios de imágenes durante el embarazo. La planificación de la intervención convocó a diversos estamentos de un hospital público chileno y a especialistas de varias instituciones e incluyó disecciones en preparaciones anatómicas de onfalópagos mortinatos. La separación se realizó a los 6 meses de vida, en una intervención en 3 etapas, de más de 18 horas de duración, posterior al delicado tratamiento de los efectos hemodinámicos de la transfusión inter-gemelar.

Con un seguimiento de 24 meses, el crecimiento y desarrollo psicomotor de ambos niños ha sido satisfactorio.

La convocatoria de un equipo multidisciplinario, la preparación de la intervención quirúrgica y el detallado estudio de imágenes concluyeron en una separación quirúrgica exitosa con sobrevida de ambos hermanos.

\section{Descripción del caso, diagnóstico y estudio}

Durante la primera gestación de una adolescente sana de 17 años se diagnosticó en control ecográfico rutinario a las 18 semanas de gestación un embarazo gemelar no consanguíneo con fetos masculinos que estaban unidos ventralmente. $\mathrm{Su}$ estudio antenatal con ecografía-doppler y resonancia nuclear magnética $(\mathrm{RM})$ (Figura 2) determinó que se trataba de siameses onfalópagos, unidos ampliamente en tórax y abdomen, con fusión completa de sus

Tabla 1. Clasificación y frecuencia de gemelos siameses de acuerdo al sitio de unión

\begin{tabular}{|c|c|c|c|}
\hline \multicolumn{2}{|c|}{ Tipo de fusión (frecuencia) } & \multirow{2}{*}{$\begin{array}{l}\text { Sitio de unión } \\
\text { Unión lateral }\end{array}$} & \multirow{2}{*}{$\begin{array}{l}\text { Estructuras más frecuentemente compartidas } \\
\text { Ombligo, abdomen inferior, tracto genitourinario, alteraciones } \\
\text { anorrectales }\end{array}$} \\
\hline Parápagos & $(28 \%)$ & & \\
\hline Toracópagos & $(19 \%)$ & Tórax a ombligo & Esternón, diafragma, hígado, corazón \\
\hline Onfalópagos & $(18 \%)$ & Abdomen-Ombligo & Nunca fusión cardíaca. Hígado, íleon terminal y colon \\
\hline Isquiópagos & $(11 \%)$ & Caderas & Tubo digestivo distal, tracto genitourinario \\
\hline Cefalópagos & $(11 \%)$ & Encéfalo & \\
\hline Pigópagos & $(6 \%)$ & Unidos por el sacro & Sacro y coxis, huesos pélvicos, ano, recto \\
\hline Craniópagos & $(5 \%)$ & Cráneo & Cráneo, meninges, senos venosos \\
\hline Raquípagos & $(2 \%)$ & Columna & Anomalías vertebrales. Defectos tubo neural \\
\hline
\end{tabular}




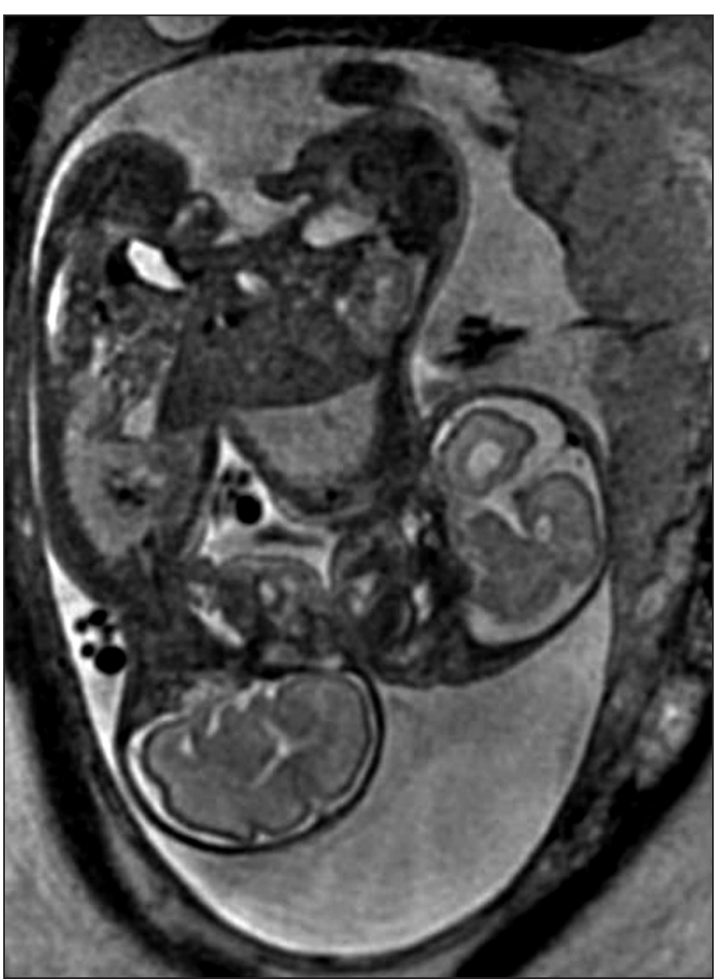

Figura 2. Fotografía de la Imagen por Resonancia Nuclear Magnética intrauterina de los gemelos.

hígados con estructuras con flujo venoso que cruzaban de un feto al otro. Su seguimiento ecográfico prenatal hacía sospechar un flujo unidireccional del gemelo I (G-I) al gemelo II (G-II), que no repercutió inicialmente en el crecimiento fetal ni en el desarrollo cardíaco de los gemelos. Se evaluó el caso en equipo multidisciplinario y se controló el embarazo en el Centro de Diagnóstico e Investigaciones Perinatales (CEDIP) del Hospital Dr. Sótero del Río. Se discutió la viabilidad y factibilidad de separación post natal de los niños y se evaluó la capacidad local de resolución del caso. Se informó siempre el pronóstico reservado a los padres y familiares. Se controló el desarrollo fetal con ecografías quincenales y se hospitalizó a la madre a las 32 semanas de embarazo para realizar maduración pulmonar con corticoides, mantener una vigilancia estricta y preparar el parto con interrupción programada planificada para las 38 semanas de gestación. Sin embargo, la madre presentó una rotura prematura de membranas, por lo que la intervención cesárea se practicó a las 35 semanas. Los gemelos nacieron sin incidentes con apgar 7-8 (ambos) y un peso conjunto de $4,2 \mathrm{~kg}$.

El tratamiento post natal inicial fue delicado y empírico. El G-I evolucionó con una oligoanuria persistente y refractaria al uso de diuréticos a causa del paso de una proporción significativa de su volemia al G-II. Éste, por su parte, desarrolló una insuficiencia cardíaca congestiva e hipertensión arterial sistémica por hipervolemia, dada la extensa comunicación venosa hepática. El tratamiento simultáneo de ambos hermanos estableció un fino equilibrio entre terapias antagónicas con un lecho vascular común y planteó un dilema en la elección del momento de separación, pues los hermanos crecieron en forma asimétrica, con progresivo riesgo de daño renal en el G-I y crecimiento de cavidades cardíacas en su hermano (G-II). Se estableció un equipo de trabajo multidisciplinario con reuniones periódicas de preparación de la intervención y se decidió diferir la cirugía, pese a sugerencias en la literatura en sentido contrario ${ }^{3,6}$. Se privilegió ganar tiempo para distender la piel con expansores cutáneos y asegurar una adecuada cobertura cutánea post-separación, elemento fundamental en el pronóstico posterior.

En la $2^{\mathrm{a}}$ semana de vida, se realizó una angiografía por tomografía axial computada (AngioTAC) (Figuras 3a y b), que mostró la extensa fusión de los hígados y al menos dos comunicaciones venosas entre el G-I y el G-II. Los pedículos portales y el drenaje venoso de cada hígado eran independientes. Se descartó una fusión intestinal y de las vías biliares mediante estudio baritado y cintigráfico hepatobiliar (Figura 3d) respectivamente. Una angiografía por RM con reconstrucción tridimensional (Figura 3c) permitió visualizar los planos del curso de las comunicaciones venosas intrahepáticas y los volúmenes de ambos hígados.

Se convocó un equipo de cirujanos pediátricos, plásticos, cardiovasculares y hepatobiliares de distintas instituciones para realizar este desafío. La preparación incluyó disecciones sobre onfalópagos mortinatos (Figura 4) con estudios radiológicos de las preparaciones anatómicas. Se adecuaron los pabellones quirúrgicos, los servicios de apoyo, la unidad de cuidados intensivos y los recursos logísticos para la monitorización intra-operatoria.

A los 4 meses, se les instaló los expansores cutáneos; intervención que permitió evaluar las dificultades de accesos venosos y de la vía aérea en el pabellón quirúrgico. Se infundieron semanalmente los expansores cutáneos con solución salina, alcanzando un volumen final de $550 \mathrm{ml}$ en el G-I y de 600 $\mathrm{ml}$ en el G-II.

\section{Cirugía de separación}

La separación se realizó, de acuerdo a lo planificado, a los seis meses de vida. Bajo anestesia general (con 2 equipos de anestesistas independientes), con los gemelos sobre sus flancos con su aspecto anterior hacia arriba (según nomenclatura 


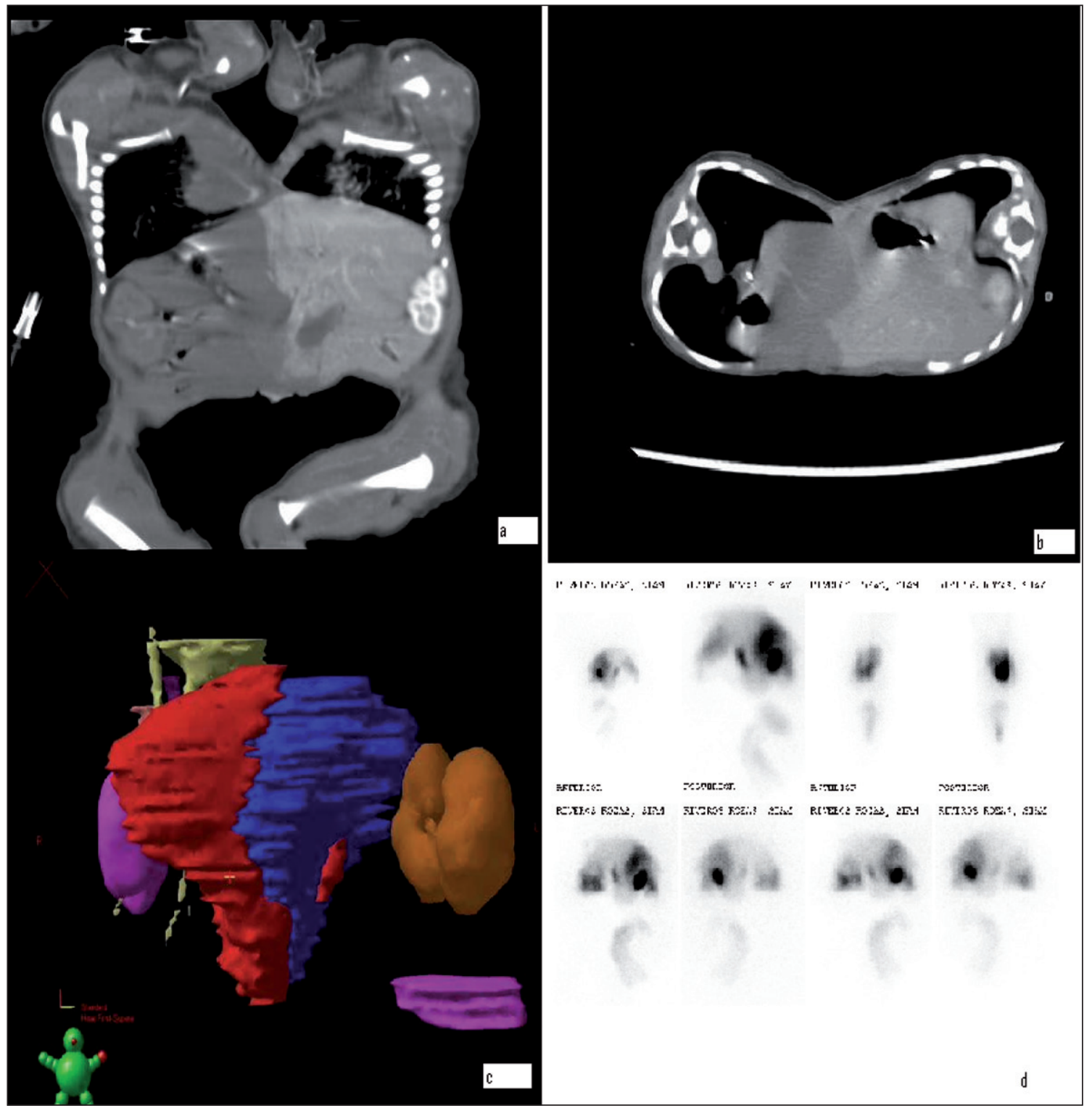

Figura 3. Fotografía de la Tomografía Axial Computada con contraste intravenoso en el gemelo I. (a) Corte sagital de los gemelos. (b) Corte transversal donde se aprecia contraste en una vena del G-II, cuando se inyectó el G-I a la derecha de la figura. (c) Imagen de la reconstrucción tridimensional (3D) de una Angiografía por Resonancia Nuclear Magnética. (d) Fotografía del cintigrama hepatobiliar, en la que se identifican las vesículas biliares y duodenos separados.

de consenso) (flanco derecho de un gemelo-lateral izquierdo del otro) (Figura 5a) y con monitorización invasiva (que incluyó ecocardiografía transesofágica en ambos hermanos), se procedió al vaciamiento de los expansores cutáneo, sin retirarlos (Figura $5 b$ ). Luego, se inició la separación quirúrgica con una incisión amplia en toda la extensión de la unión toraco-abdominal con exploración y confirmación de las zonas fusionadas.
La separación se realizó en 3 etapas mayores con períodos de estabilización de los gemelos entre ellas:

a) Etapa de separación torácica: Se procedió a la división de las estructuras de la pared del tórax, dividiendo las estructuras óseas con un abordaje extra pleural y extra peritoneal, de modo de evitar la penetración de las cavidades pleurales. Se preservaron las estructuras óseas más posteriores respecto 
a la posición de los gemelos, para mantener la estabilidad corporal de ambos, evitando tensiones sobre el puente hepático común y estructuras vasculares. El esternón estaba fusionado en sus $2 / 3$ caudales y se dividió completamente. Se realizó apertura del pericardio del G-I, constatándose que las cavidades pericárdicas eran independientes (Figura 6), sólo unidas por un defecto circular de alrededor de $10 \mathrm{~mm}$. Ambos corazones y estructuras vasculares estaban separados por completo y con morfología normal.

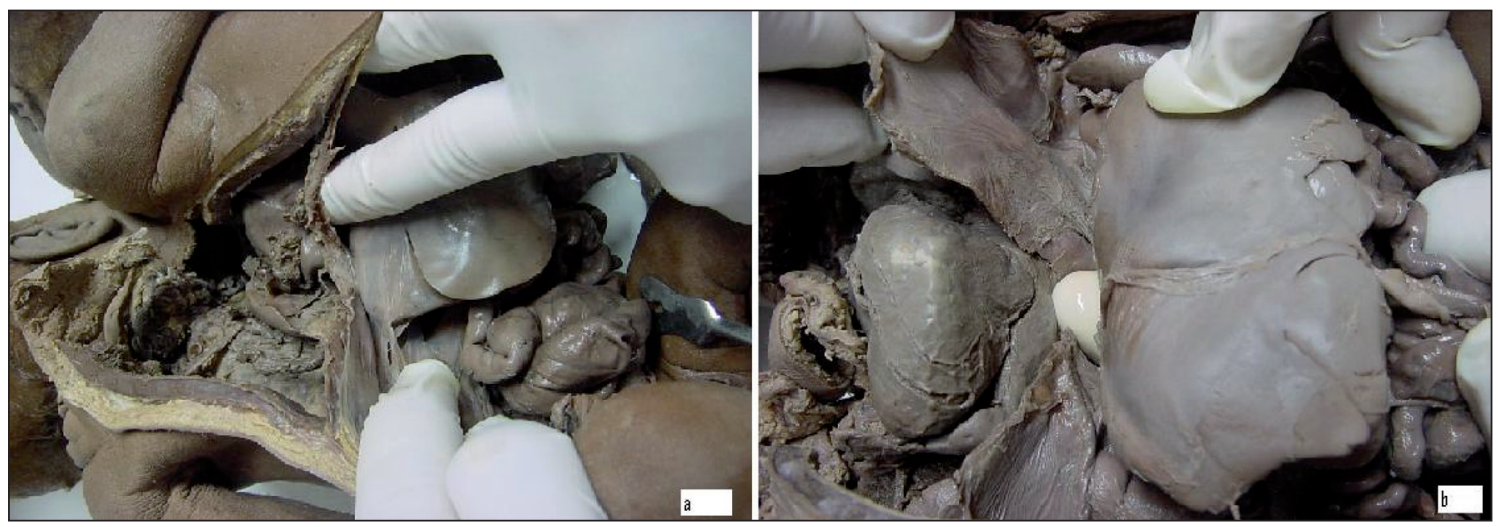

Figura 4. (a) Disección y separación de preparados anatómicos de siameses onfalópagos. (b) Extensa fusión hepática similar a la de nuestros gemelos.

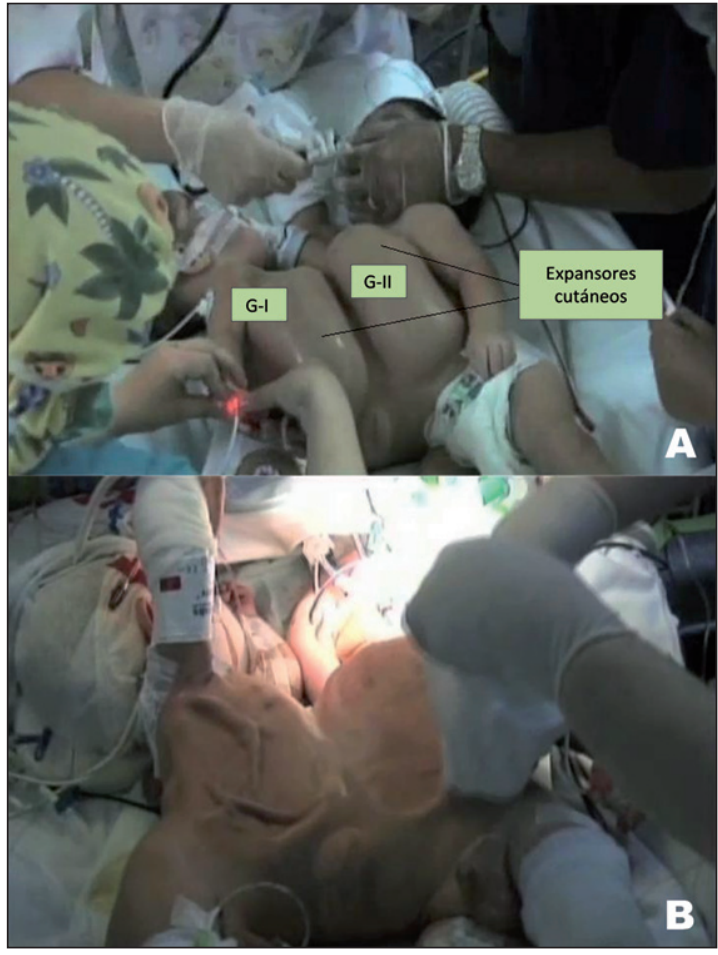

Figura 5. (a) Posición de los gemelos en el pabellón quirúrgico, el G-I se encuentra a la izquierda de la foto. Se aprecian los expansores cutáneos inflados, (b) Expansores cutáneos desinflados, antes de la incisión.

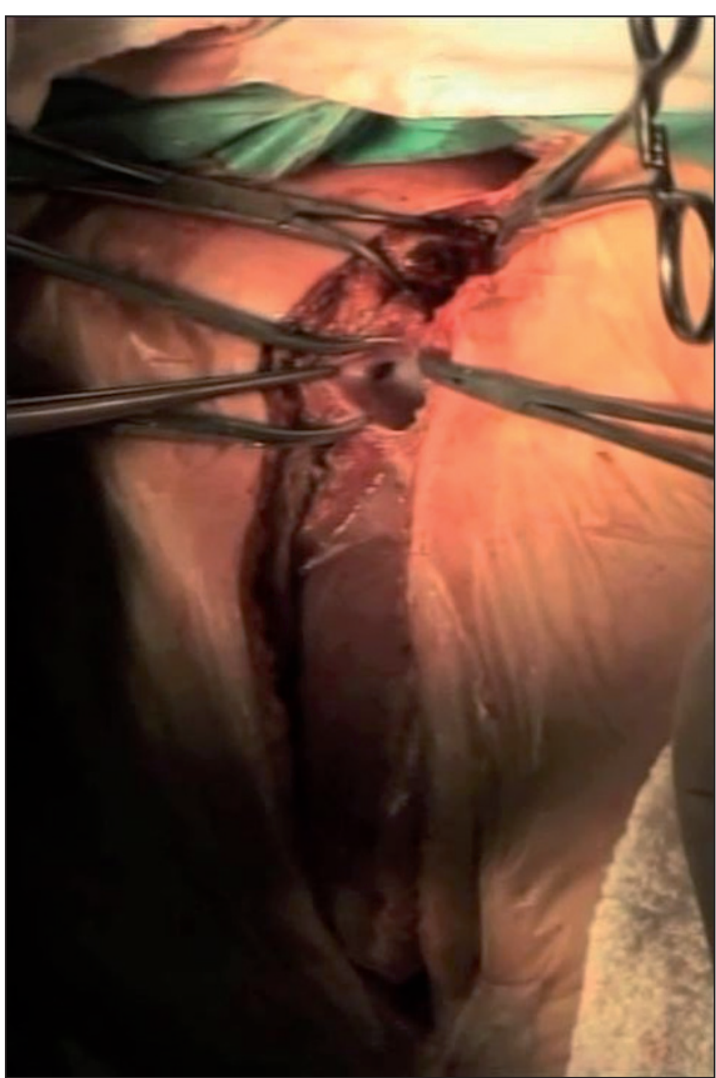

Figura 6. Acercamiento post incisión inicial y llegada al pericardio común, la extensión de la incisión torácica permite apreciar la extensa fusión hepática. 
b) Etapa de separación abdominal: Se inicia por división anterior de la fusión diafragmática, con el fin de facilitar el abordaje de los hígados fusionados. Se comprueba separación completa de la vía biliar, con vesículas independientes. Se confirmó la independencia de ambos duodenos y tubos digestivos. Luego se expuso ampliamente la fusión hepática que medía $12 \mathrm{~cm}$ en el eje céfalo-caudal. Se practicó una colecistectomía al G-II dado que su vesícula cruzaba el plano de transección. Luego se localizaron las venas que cruzaban de un gemelo al otro con ecografía-doppler. Una de las venas (la mayor) comunicaba el sistema portal del G-I con la vena hepática izquierda del G-II a través del conducto de Arancio. La otra, drenaba enteramente un segmento hepático del G-I hacia el G-II. Su volumetría, hacía preveer la exéresis de este segmento al quedar sin drenaje venoso. La transección parenquimatosa se realizó con tijera LigaSure precise ${ }^{\circledR}$ (Covidien) y pinza bipolar. En este tiempo se monitorizó la repercusión hemodinámica de la interrupción de la transfusión entre ellos, mediante el ecocardiógrafo transesofágico, vigilando además la eventualidad de embolias aéreas. Se seccionaron ambas venas (la mayor de $12 \mathrm{~mm}$ ) sin incidentes y se continuó la división del hígado con mínimo sangrado (Figura 7). Posteriormente, se resecó el segmento hepático (del G-I) que quedó sin drenaje venoso. Se descartaron otras alteraciones anatómicas en el abdomen y finalmente, luego de estabilización y de otorgar un tiempo de adaptación hemodinámica a los niños, se procedió a la sección de la unión de tejidos blandos y costales de la región posterior (flanco izquierdo de uno y flanco derecho del otro), separando completamente a los gemelos.

Se trasladó uno de ellos a otra mesa quirúrgica individual, en el mismo pabellón, con equipos quirúrgicos y anestésicos independientes (Figura 8).
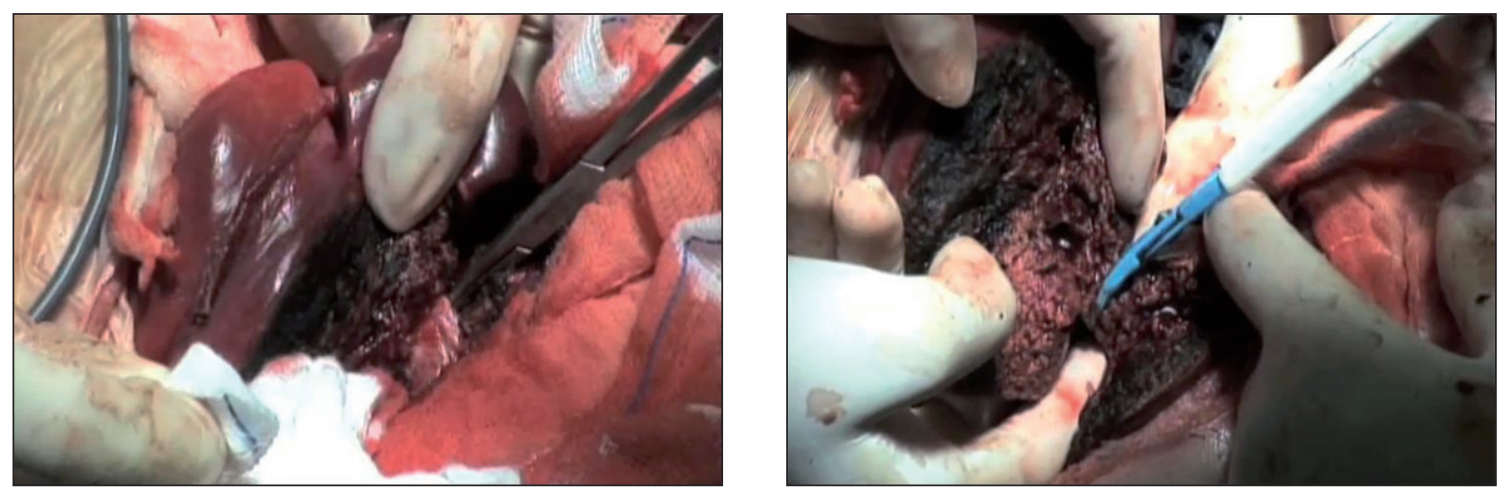

Figura 7. (a) Se ilustra el momento en que se encuentra y se aisla la vena comunicante mayor (12 mm de ancho), antes de realizar las pruebas hemodinámicas de pinzamiento de la misma. (b) Se han seccionado ambas venas comunicantes y se está terminando la transección del parénquima hepático fusionado.
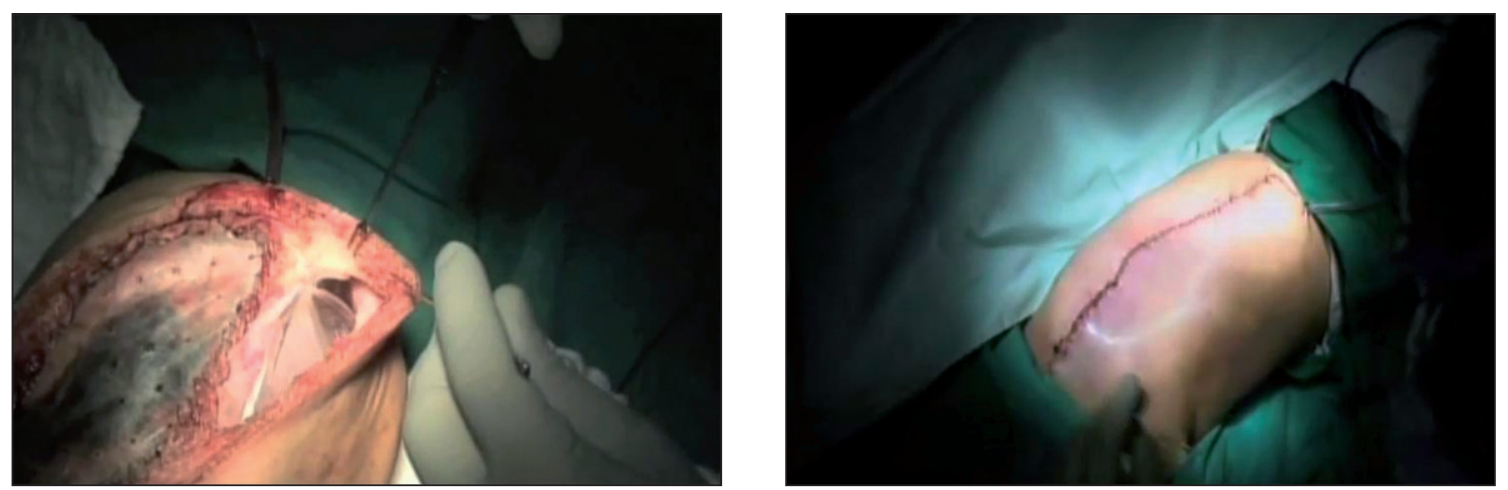

Figura 8. (a) Cierre de la pared torácica y abdominal con malla biológica mixta, se inicia el talle de colgajos cutáneos para poder cubrir completamente la malla. (b) Cierre completo de la incisión tóraco-abdominal al final de la intervención de uno de los gemelos. 
c) Etapa de reconstrucción de la pared: Con los hermanos en mesas operatorias distintas y 2 equipos simultáneos, se procedió a la revisión minuciosa del intestino y resto de estructuras abdominales en cada hermano sin encontrar otras malformaciones. Se practicó en ellos la reconstrucción y cierre del gran defecto abdominal y torácico con malla biológica mixta (polidioxanona + matriz de colágeno acelular) Surgisis ${ }^{\circledR}$, Biodesign $₫$ (Figura 8a). Además se reparó y reconstruyó el diafragma de cada hermano con la misma malla. Al final, se retiraron los expansores y se procedió a levantar colgajos cutáneos que permitieron el cierre primario de la piel sin tensión (Figura 8b). Se realizó una plastía umbilical en ambos hermanos y se dejó un drenaje abdominal en cada niño.

La intervención duró 18 horas.

\section{Evolución post-operatoria}

Los principales eventos posteriores a la prolongada intervención y las complicaciones se resumen en la Tabla 2. Ambos hermanos presentaron fístulas biliares de bajo débito conducidas con aspiración y drenaje que se resolvieron en forma espontánea en los primeros 15 días. La función hepática no se comprometió en ninguno de ellos. El G-I requirió de una re-intervención por un íleo mecánico de intestino delgado por bridas a los 45 días de la separación. Su función renal se normalizó rápidamente. La cobertura cutánea de los 2 hermanos, presentó una dehiscencia parcial menor que se trataron con sistemas de curación por aspiración al vacío con

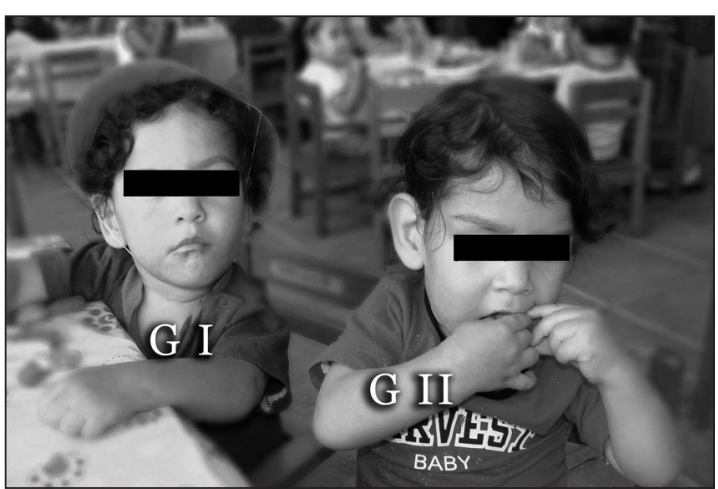

Figura 9. Fotografía de los gemelos al cumplir 2 años de vida, es decir, 18 meses después de la cirugía de separación.

buena evolución. No se requirió de injertos cutáneos adicionales.

El alta médica fue estrictamente a los 60 días de la intervención para ambos niños, sin embargo, por razones sociales, debieron permanecer en el recinto hospitalario 2 meses más.

Actualmente, con más de 2 años de edad y a 26 meses de la separación, ambos hermanos se encuentran en excelentes condiciones generales en controles ambulatorios (Figura 9), con buen desarrollo psicomotor, sin secuelas neurológicas. Ambos presentan una deformidad moderada del tórax (pectus carinatum) sin repercusión clínica, esperable por su antigua fusión esternal. Están en tratamiento ortopédico con compresión y pudiesen requerir cirugía correctiva cosmética en la adolescencia.

Tabla 2. Evolución post-operatoria después de la Separación de los Gemelos Onfalópagos

\begin{tabular}{lll}
\hline & G-I & G-II \\
\hline VM & Sí, 5 días & Sí, 9 días \\
AVNI & Sí, 4 días & Sí, 13 días \\
Drogas vasoactivas & Sí & Sí \\
Tolerancia enteral & Adecuada & Adecuada \\
Complicaciones & & \\
- Fístula Biliar Externa & Sí, tratamiento médico & Sí, tratamiento médico \\
- Íleo Mecánico & Sí, por adherencias & No \\
- Paresia EESS & No & Sí, autolimitada izq. \\
Reoperaciones & Sí, por íleo mecánico & No \\
DSM (8 m) & Retraso leve & Retraso leve \\
Test potenciales auditivos & BERA: normal & BERA: normal \\
Seguimiento & 26 meses & 26 meses \\
\hline
\end{tabular}

VM: ventilación mecánica; AVNI: Asistencia ventilatoria no-invasiva; EESS: Extremidades superiores; DSM: Desarrollo Psicomotor; BERA: (Abreviación del inglés, brainstem auditory evoked response: Respuesta auditiva evocada). 


\section{Discusión}

Entre los gemelos monocigóticos, los siameses representan la anomalía más compleja y tiene su origen embriológico en la falla de la división del blastocisto $^{5,6}$. Más recientemente, se ha postulado también un segundo mecanismo por unión secundaria de 2 discos embrionarios separados ${ }^{7}$. La presentación clínica puede ir desde la unión de tejidos ectodérmicos (piel y fanéreos) hasta casos donde uno de los gemelos es contenido en el otro (gemelos parásitos) $)^{1,5}$.

El diagnóstico suele realizarse durante el embarazo por ultrasonografía, ya desde la $7^{\mathrm{a}}$ semana de edad gestacional (SEG); con mayor frecuencia después de la $12^{\text {a }} \mathrm{SEG}^{8,9}$. En nuestro caso, el diagnóstico se sospechó a la $18^{\text {a }}$ SEG y una vez confirmado que correspondían a un par de siameses onfalópagos, se enfocó su estudio con ecografía-doppler y RM fetal para determinar los detalles anatómicos de las estructuras compartidas. Así se demostró una importante fusión hepática con circulación venosa unidireccional de un feto al otro. Este hallazgo, nos planteó la búsqueda de otras malformaciones asociadas según lo descrito por otros autores ${ }^{3-6}$ y nos alertó a confirmar en el curso del embarazo la presencia de un Síndrome de Transfusión Gemelo-Gemelar (STGG). Éste, ocurre a través de fístulas arteriovenosas o veno-venosas en el parénquima de la fusión hepática ${ }^{6,10}$ y no a través de la placenta, como clásicamente se ha descrito en embarazos gemelares monocoriónicos no fusionados ${ }^{11,12}$. El estudio antenatal debe evaluar el pronóstico de viabilidad de los fetos y la factibilidad de una separación quirúrgica exitosa posterior al nacimiento ${ }^{3,4}$.

Una vez que los niños nacieron por cesárea, se planteó la disyuntiva del momento de la separación quirúrgica. Algunos autores sugieren practicarla precozmente, aunque con resultados variables ${ }^{3,6}$. Por otro lado, también estaba descrito que la separación de siameses de urgencia, sin cobertura cutánea adecuada, es de mal pronóstico ${ }^{6,13}$. Así, se postergó el momento de la separación quirúrgica, para optimizar las probabilidades de éxito para ambos hermanos, evaluando de cerca la respuesta de los niños al complicado tratamiento médico del STGG. Esta espera permitió planificar la intervención, completar el estudio anatómico y preparar al equipo quirúrgico, aunque arriesgábamos el pronóstico renal y cardíaco de los niños, el cual, al principio, era impredecible. La evolución posterior demostró que esta estrategia fue acertada, con sobrevida de ambos niños, sin problemas de cobertura; con normalización en el G-I de su función renal y en el G-II de sus cifras tensionales con progresiva reversión del crecimiento de las cavidades cardíacas. Esta estrategia conservadora la consideramos un aporte a lo comunicado precedentemente en la literatura ${ }^{3-6}$ ya que abre otras opciones de tratamiento más planificadas.

Destacamos el estudio y disecciones de preparaciones anatómicas de onfalópagos mortinatos en la preparación del equipo, lo que fue de invaluable utilidad en la planificación técnica y del abordaje a emplear. Esta intervención tiene la particular dificultad anatómica del acceso desde los flancos de los hermanos (Figuras 5 a y b) y no desde el frente, como en cirugía abdominal tradicional. Además, la planificación de la fase reconstructiva con el objetivo de obtener una adecuada cobertura cutánea utilizando expansores dos meses antes, aseguró un adecuado cierre del defecto post-separación.

Durante la intervención, los principales problemas a enfrentar eran: una anatomía difícil de abordar, la impredecible respuesta cardíaca y renal que tendrían los gemelos posterior a la separación, la obtención de cobertura cutánea suficiente para cubrir el defecto, la posibilidad de encontrar hallazgos intra-operatorios no diagnosticados previamente y poder llegar relativamente rápido y en las mejores condiciones al tiempo quirúrgico abdominal de partición hepática. La presencia coordinada de todos los equipos y especialistas para el estrecho monitoreo de los niños (ecocardiografía endoscópica intra-operatoria, control de la temperatura corporal, vías venosas, líneas arteriales, etc) y la meticulosa separación en etapas pre-planificadas, controlaron los riesgos vitales de ambos niños.

El resultado en términos de morbilidad fue menor con sólo una re-intervención por íleo mecánico, pese a la prolongada hospitalización motivada parcialmente por la juventud y precariedad de sus padres adolescentes que requirieron de apoyo educacional aparte.

En resumen, se describe aquí el detallado estudio anatómico por imágenes y la exhaustiva preparación logística y técnica que determinaron el buen resultado de la primera separación de un par de siameses onfalópagos con STGG en el medio nacional. Esta hazaña terapéutica estuvo basada en la organización y convergencia de un vasto equipo multidisciplinario, que señala un destacado ejemplo de colaboración entre diferentes y complementarios sistemas e instituciones (público-privado) de salud.

\section{Agradecimientos}

Quisiéramos agradecer a:

- La Dirección administrativa del Servicio de Salud Sur-Oriente y del Hospital Dr. Sótero del Río.

- El personal paramédico, administrativo, médico y profesionales asociados del Centro de Diag- 
nóstico e Investigaciones Perinatales (CEDIP), de la Unidad de Neonatología, del Servicio de Cuidados Intensivos Pediátrico, del Servicio de Cirugía Infantil y Pabellones, del Banco de Sangre y Laboratorios, etc. del citado hospital.

- Los colegas y personal del Instituto de Anatomía de la Universidad de Chile.

- Los colegas y personal del Departamento de Radiología de la Facultad de Medicina de la Pontificia Universidad Católica de Chile.

- Los colegas y personal del Departamento de Radiología del Instituto Nacional del Cáncer, que nos facilitó el software para la reconstrucción tridimensional de la fusión hepática.

- Y a tantas otras personas anónimas, que gracias a su generosa y desinteresada contribución, ayudaron al logro de este hito médico-quirúrgico que enaltece nuestra medicina y nos hace como equipo estar orgullosos de ella.

\section{Referencias}

1. Mchugh K, Kiely EM, Spitz L. Imaging of conjoined twins (Review). Pediatr Radiol 2006; 36: 899-910.

2. van Der Weiden RM. The first successful separation of conjoined twins (1689). Twin Res 2004; 7: 125-127.

3. Spitz L, Kiely EM. Experience in the management of conjoined twins. Br J Surg 2002; 89: 1188-1192.

4. Mackenzie TC, Crombleholme TM, Johnson MP, Schnaufer L, Flake AW, Hedrick HL et al. The natural history of prenatally diagnosed conjoined twins. J Pediatr
Surg 2002; 37: 303-309.

5. Thompson JL, Zarroug AE, Matsumoto JM, Moir CR. Anatomy of successfully separated thoracopagusomphalopagus conjoined twins. Clin Anat 2007; 20: 814-818.

6. Klein DJ, Filler RM, Azarow KS, Geary DF. Extrauterine twin-twin transfusion affects renal function and perioperative management of conjoined twins. J Pediatr Surg 1998; 33: 354-356.

7. Kaufman MH. The embryology of conjoined twins. Childs Nerv Syst 2004; 20: 508-525.

8. Pajkrt E, Jauniaux E. First-trimester diagnosis of conjoined twins. Prenat Diagn 2005; 25: 820-826.

9. Basgül A, Kavak ZN, Sezen D, Basgul A, Gokaslan H. Thoraco-omphalopagus conjoined twins detected at as early as 9 weeks of gestation: transvaginal twodimensional ultrasound, color doppler and fetoplacental doppler velocity waveform findings. Fetal Diagn Ther 2006; 21: 477-480.

10. Spitz L. Conjoined twins (Review). Prenat Diagn 2005; 25: 814-819.

11. Chan JC, Somerset DA, Ostojic N, Cox P, Young P, Brueton $\mathrm{L}$ et al. Omphalopagus conjoining and twin-twin transfusion syndrome. Prenat Diagn 2005; 25: 612-614.

12. Minakami H, Honma Y, Matsubara S, Uchida A, Shiraishi $\mathrm{H}$, Sato I. Effects of placental chorionicity on outcome in twin pregnancies. A cohort study. J Reprod Med 1999; 44: 595-600.

13.- Meyers R, Matlak M. Biliary tract anomalies in thoraco-omphalopagus conjoined twins. J Pediatr Surg 2002; 37: 1716-1719. 